\title{
RETRACTED ARTICLE: LncRNA XIST inhibits ovarian cancer cell growth and metastasis via regulating miR-150-5p/PDCD4 signaling pathway
}

\author{
Shuli Wang ${ }^{1} \cdot$ Guanzhen $\mathrm{Li}^{2}$ (D) \\ Received: 30 April 2019 / Accepted: 4 January 2020 / Published online: 13 January 2020 \\ (C) Springer-Verlag GmbH Germany, part of Springer Nature 2020
}

The Editor in Chief retracted this article (1) because of significant concerns regarding a number of Figures presented in this work, which question the integrity of the data.

Figure $2 \mathrm{C}$ and $6 \mathrm{~B}$ - some plots appear to have been re-use between the two figures. Additionally, there is a close similarity between a scatter plot in these two figures and one published in an earlier article by unrelated authors (2)

Figure 8B (sh-XIST) and C (shRNA) -these images appear to have been published previously in an unrelated publication (3)

The authors were unable to provide raw data and stated that the figures were obtained through a commercial lab hired to perform some of the experiments for this study.

Author Guanzhen Li agrees to this retraction. Author Shuli Wang has not responded to any correspondence from the editor or publisher about this retraction.

Electronic supplementary material The online version of this article (https://doi.org/10.1007/s00210-020-01808-2) contains supplementary material, which is available to authorized users.

Guanzhen Li

K15588650568@163.com

1 Department of Imaging, Provincial Hospital Affiliated to Shandong University, Jinan 250000, Shandong, China

2 Department of Oncology, Provincial Hospital Affiliated to Shandong University, Jinan 250000, Shandong, China
The online version of this article contains the full text of the retracted article as electronic supplementary material.

\section{References}

1) Wang, S., Li, G. LncRNA XIST inhibits ovarian cancer cell growth and metastasis via regulating miR-150-5p/PDCD4 signaling pathway. Naunyn-Schmiedeberg's Arch Pharmacol (2020). https://doi.org/10.1007/s00210-020-01808-2

2) Wang, Q. et al. Physcion 8-O- $\beta$-glucopyranoside inhibits clear-cell renal cell carcinoma bydownregulating hexokinase II and inhibiting glycolysis. Biomedicine \& Pharmacotherapy (2018) https://doi.org/10.1016/j.biopha.2018.05.013

3) Liu, B., Yu, S. Amentoflavone suppresses hepatocellular carcinoma by repressing hexokinase 2 expression through inhibiting JAK2/STAT3 signaling. Biomedicine \& Pharmacotherapy (2018) https://doi.org/10.1016/j.biopha.2018. 07.177 